\title{
Study on Rough Filtration Plus Slow Sand Filtration Techniques for Cellar Water of Villages and Towns in Northwest China
}

\author{
Guozhen Zhang ${ }^{1, a}$, Li Zhao ${ }^{2, b}$,Fuping Wu ${ }^{1, c}$, Miao Zhang ${ }^{2, d}$, Zhifang Yue ${ }^{2, e}$, \\ Qian Wang ${ }^{2, f}$, Shichao Yang ${ }^{2, g}$, Jiafu Wang ${ }^{2, \text { h }}$, Shiyu Gong ${ }^{2, ~ i ~}$ \\ ${ }^{1}$ School of Environmental and Municipal Engineering, LanzhouJiaotong University, Lanzhou \\ 730070, China \\ ${ }^{2}$ No.88, Anning West Road, Anning District, Lanzhou City, Gansu Province, China

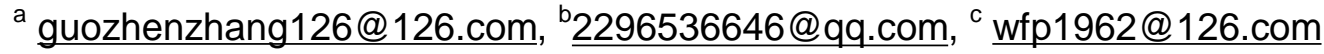

Keywords: cellar water; rough filtration; slow biological filtration; turbidity.

Abstract: Based on the turbidity, lower temperature and micro-pollution of cellar water in villages and towns in northwest China, removal efficiency of turbidity. Results showed that the turbidity in yielding water became stable and the average removal rate reached 92\%, 20\%, 32\%, 32\%, 22\% respectively after operating integrate technology for 25 days. After cellar water was treated through rough filtration plus slow biological filtration technics, all indexes above accorded with the standards of drinking water quality. Thus, this integrate technology can be used to reprocess the diminutive and scattered cellar water of villages and towns in northwest China.

In recent years, effectively accumulated the cellar and made full use of the natural rainfall by organizing and implementing the rain collector engineering in arid and semi-arid area of Gansu province, to a great extent, played an important role in easing the shortage of water resources situation, in development of local economy and in the improvement of living ${ }^{[1]}$.

Rainwater stored in the cellar was polluted by solid debris (trash, animal waste, etc), air fallout, chemical fertilizers, pesticides, vehicle emissions and other pollution from human activity. In addition, the rainwater stored in the cellar for a long term always cause water metamorphic and stale, drinking of which will be pernicious to human beings and livestock. Our tests found that cellar water, in which chrominance and turbidity is terrible, suffered from heavy metal pollution in different degrees was smelly and had the fishy smell while microbe, organic matter and total nitrogen in water always exceeded the standards of drinking water. The water will not be qualified for drinking without necessary cleansing measures ${ }^{[2]}$. 
According to the characteristics of the units, this paper developed laboratory research, optimization and integration for rough filtration plus slow sand filtration with the advantages of low cost, simple operation and being as a dispersive unit. And this paper is also set up to test the removal efficiency of the rainwater storage through the experimental study, and tries to seek a solution to problems of safety for drinking water in northwest arid area.

\section{Experimental section}

\section{Devices and parameters}

The experiment devices as shown in figure 1 below

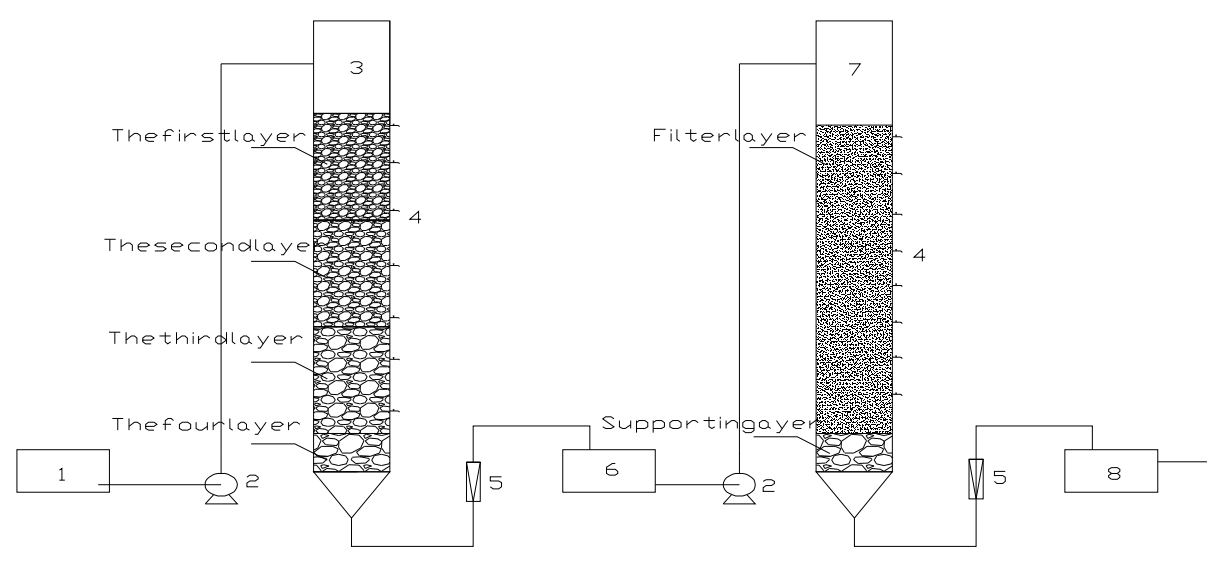

1-feedwater box;2-water pump;3- crude filter column;4-entrance to sampling;5-flowmeter;6-water box;7- Zeolite biological slow filter column;8-water store box

Fig. 1 The experiment devices

Basic parameters of experiment devices: crude filter column filled with pebbles, three layers filling, size and filter layer thickness from top to bottom are as follows: the first layer particle size is about $5 \sim 10 \mathrm{~mm}$, filter layer thickness is about $350 \mathrm{~mm}$; The second particle size is about $10 \sim 15$ $\mathrm{mm}$, filter layer thickness is about $350 \mathrm{~mm}$; The third is about $15 \sim 20 \mathrm{~mm}$, filter layer thickness is about $350 \mathrm{~mm}$; Supporting layer particle size is about $20 \sim 25 \mathrm{~mm}, 300 \mathrm{~mm}$ thick; Sand surface above water depth is $250 \mathrm{~mm}$. Crude filter column filter speed is about $\mathrm{v}=0.16 \mathrm{~m} / \mathrm{h}$. Zeolite biological slow filter column filled with filter material the activation zeolite, particle size is about $0.2 \sim 0.5 \mathrm{~mm}$, filter layer height is about $1000 \mathrm{~mm}$; The material of supporting layer is gravel and the particle size is about $2 \sim 4 \mathrm{~mm}$, the thickness of supporting layer is $50 \mathrm{~mm}$. Filter speed is $\mathrm{v}=$ $0.16 \mathrm{~m} / \mathrm{h}$. 


\section{Water quality and analysis}

\section{The water quality}

According to the quality situation of cellar water in villages and towns in northwest China ${ }^{[3-5]}$, this experiment was conducted by simulating northwest cellar rainwater for raw water with the collection distributions of local face soil, mimicking the northwest dry area of storage set of rain, water quality condition worthy as is shown in table 1.

Table 1 Water quality index

\begin{tabular}{|c|r|r|r|}
\hline $\begin{array}{c}\text { temperature } \\
\left({ }^{\circ} \mathrm{C}\right)\end{array}$ & $\mathrm{PH}$ & $\begin{array}{r}\text { turbidity } / \mathrm{NTU} \\
(\mathrm{mg} / \mathrm{L})\end{array}$ \\
\hline $15 \sim 26$ & $7.05 \sim 8.14$ & $10 \sim 100$ & $0.4 \sim 0.6$ \\
\hline $\mathrm{UV} 254$ & $\mathrm{COD}_{\mathrm{Mn}}$ & conduction rate & total amount of \\
$(\mathrm{mg} / \mathrm{L})$ & $(\mu \mathrm{s} / \mathrm{cm})$ & bacteria $(\mathrm{CFU} / \mathrm{mL})$ \\
\hline $0.1 \sim 0.337$ & $5.0 \sim 6.0$ & $112 \sim 145$ & $1500 \sim 87000$ \\
\hline
\end{tabular}

\section{Test method}

This paper mainly analyzed the turbidity, $\mathrm{COD}_{\mathrm{Mn}}$, ammonia nitrogen, $\mathrm{UV}_{254}$ and chromium. Turbidity was tested by SGZB type portable digital turbidity meter; Determination of COD, the potassium permanganate was used; To tested $\mathrm{NH}_{4}{ }^{+}-\mathrm{N}$, the reagent, ultraviolet spectrophotometry was used; For $\mathrm{UV}_{254}, 721$ ultraviolet spectrophotometry was used; The total bacterial count we used the culture dish count method; Chrome with second benzene carbon was analyzed by two hydrazine spectrophotometry ${ }^{[6]}$, according to the Standard Analysis Methods of Water and Wastewater

\section{Fourth Edition.}

\section{Method of operation}

The experiment was conducted by the way of continuous flow constant speed filter, for crude filter column and biological slow filter, without reverse washing. The feedwater box from coarse to variation of filter column top into thick filter column, crude filter water column by glass rotor flow meter control flow into the water box, then through ascension pump up to zeolite slow filter column, from the top to filter column, zeolite slow filter water column by glass rotor flow meter storage in clear water tank. Sampling and analysis were processed every day to inspecting the outlet water index, such as turbidity, $\mathrm{COD}_{\mathrm{Mn}}$, ammonia nitrogen, $\mathrm{UV}_{254}$, chromium removal efficiency of filter bed and growth in the integrated process. 


\section{The results and discussion}

\section{The treatment effect of the cellar water by rough filtration}

Due to the biological slow sand filtration requires the turbidity of water under $10 \mathrm{NTU}$, and rough filtration can effectively cut into the water pollution load, especially can effectively reduce turbidity of water and reduce the slow sand filtration feed water load. Therefore, the experiment used two different turbidity water 103 NTU and 53 NTU reached the turbidity removal efficiency of rough filtration device.

Turbidity removal efficiency of cellar rainwater by rough filtration column at the 103 NTU

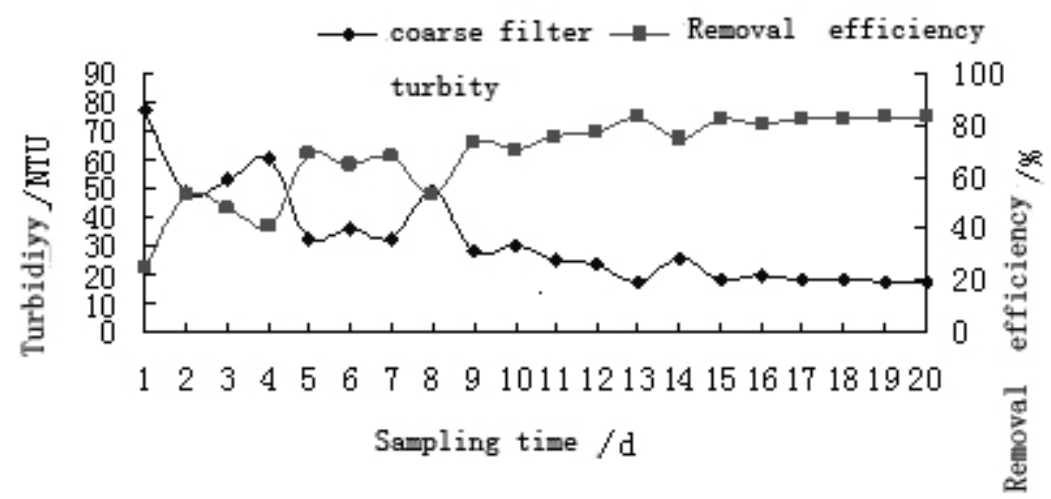

Fig. 2 Turbidity removal efficiency of rough filtration column at the 103 NTU

As shown in figure 2, when the turbidity value of water inflow during rough filtration was 103 NTU, the effluent turbidity rose and fell along with the filtering time, run before seven days effluent turbidity value was volatile, effluent turbidity maximum of 77 NTU, turbidity removal efficiency of the filter bed was unstable, removal affection is not obvious, as the filtering time extended, the effluent turbidity value fluctuation decreased, the turbidity removal efficiency of filter bed enhanced. Operation after 14 days effluent turbidity value mainly became stable, turbidity value ranged from 17 to 19 NTU, turbidity removal efficiency of filter bed were at the top, the removal rate was about $82 \%$. 
Turbidity removal efficiency of cellar rainwater by rough filtration column at the 53 NTU

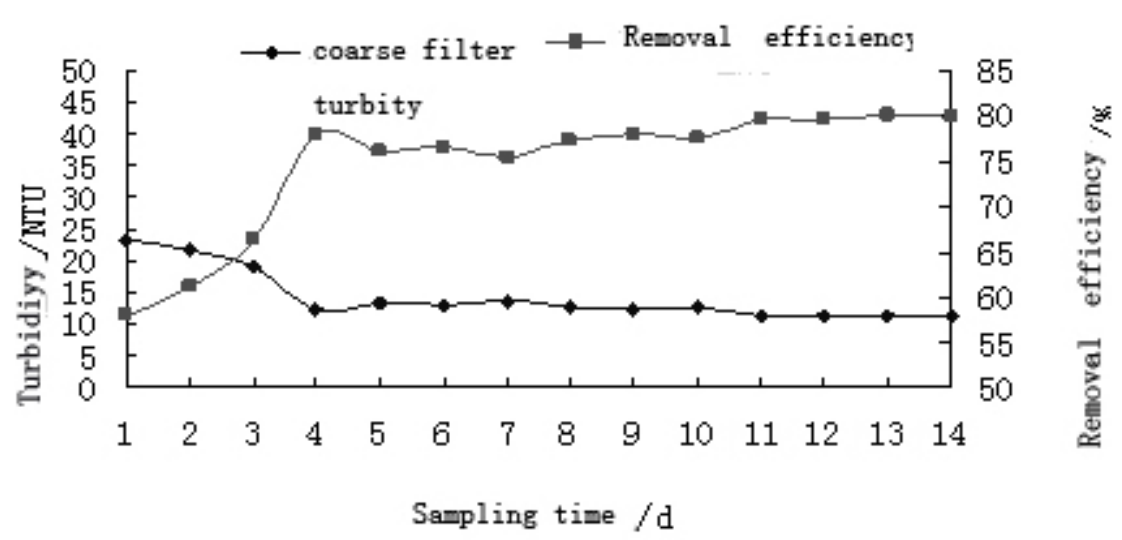

Fig. 3 Turbidity removal efficiency of rough filtration column at the 53 NTU

As shown in figure 3, when the turbidity value of water inflow during rough filtration was 53 NTU, running seven days after, the effluent turbidity value was volatile, as the continuation of the filtering time, there was a descending trend. Filtration process to run up to 8 days, turbidity removal efficiency of the filter bed enhanced, and the effluent turbidity value basically became stable, turbidity value ranged from 11 to 12 NTU, turbidity removal efficiency of the filter bed was at the top, the removal rate was about $80 \%$.

Wastes mainly intercepted at the surface of the first layer of filter materials, the interception role of sublayer filter materials didn't play well. In the process of rough filtration, we did not wash the filter layer, so the surface of filter material has already intercepted a part of turbidity part of wastes, thus, after filtering process ran for eight days, the effluent turbidity became stable. This resort benefits from the first stage (turbidity for 103 NTU) filtration process, effectively shorten the stability cycle of the effluent turbidity water.

The treatment effect of the cellar water by rough filtration plus slow sand biological filtration technics during microbial mucous membrane formatting period

Microbial mucous membrane was formatting naturally on the surface of the slow sand biological filter materials with the collected cellar rainwater, water temperature was $15 \sim 26{ }^{\circ} \mathrm{C}$, filter speed was $0.16 \mathrm{~m} / \mathrm{h}$. This period lasted for about 24 days or so. 
The turbidity removal effect during microbial mucous membrane was formatting on the

\section{Filter material}

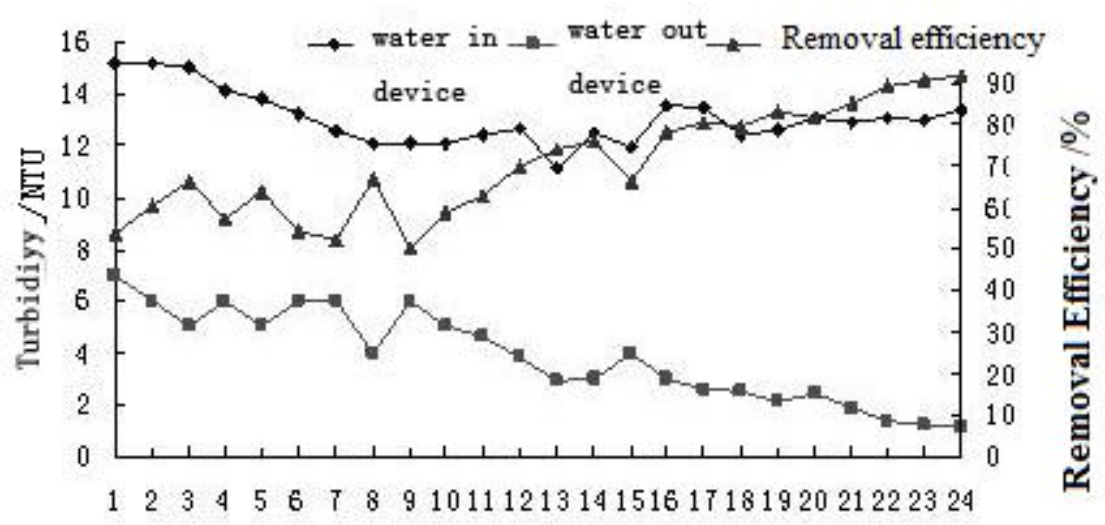

Sampling time $/ d$

Fig. 4 The removal efficiency of turbidity

As shown in figure 4, after 24 days' microbial mucous membrane formation naturally, effluent turbidity tended to stable and the turbidity removal rate increased significantly, achieved $90 \%$.

The removal effect of $\mathrm{COD}_{\mathrm{Mn}}$ during microbial mucous membrane was formatting on the

\section{Filter material}

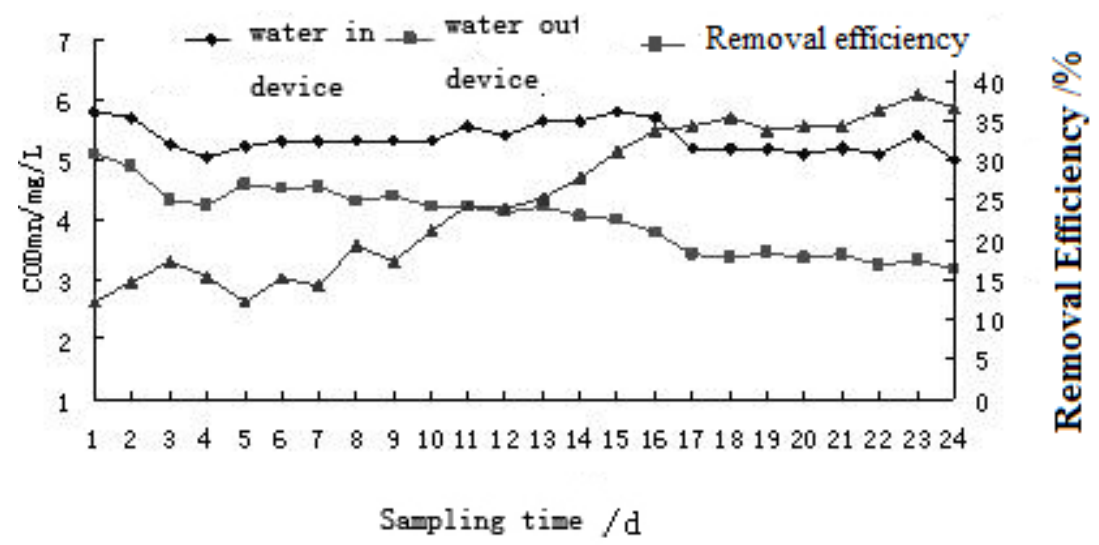

Fig. 5 The removal effect of $\mathrm{COD}_{\mathrm{Mn}}$

As shown in figure 5, after 24 days' microbial mucous membrane formation naturally, the removal rate of CODMn tended to be stable, and the removal rate above $32 \%$. 
The removal effect of ammonia nitrogen during microbial mucous membrane was formatting on the Filter material

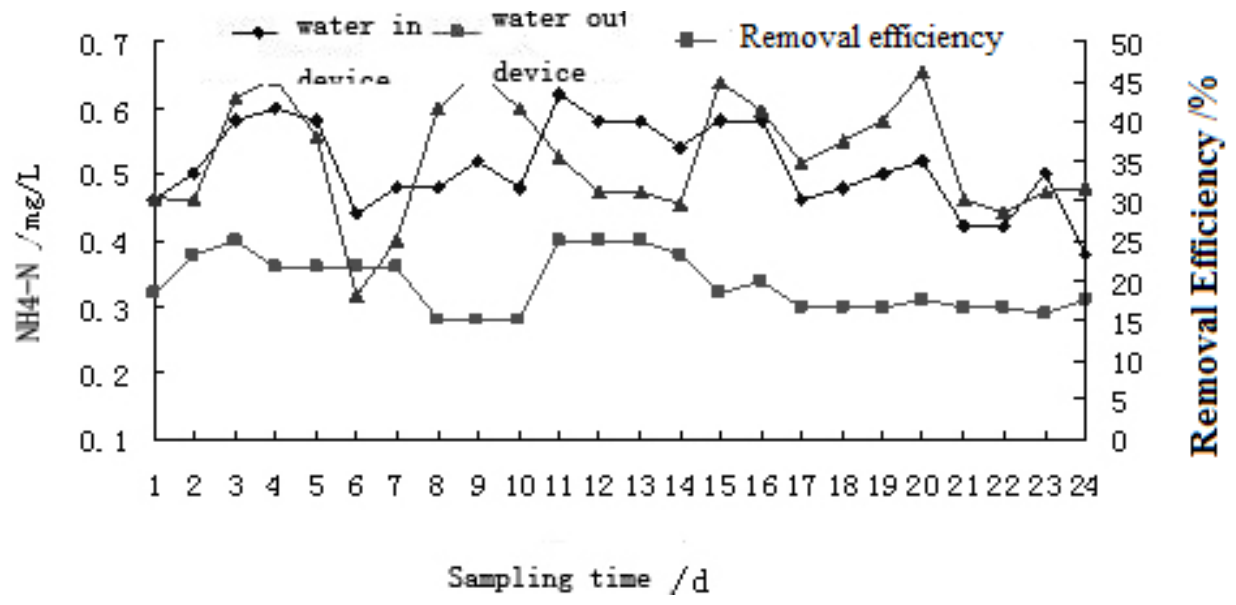

Fig. 6 The removal effect of ammonia nitrogen

After 24 days' microbial mucous membrane formation naturally, ammonia nitrogen of effluent achieved stable, ammonia nitrogen's removal was very obvious, above $25 \%$.

The removal effect of $U^{254}$ during microbial mucous membrane was formatting on the Filter material

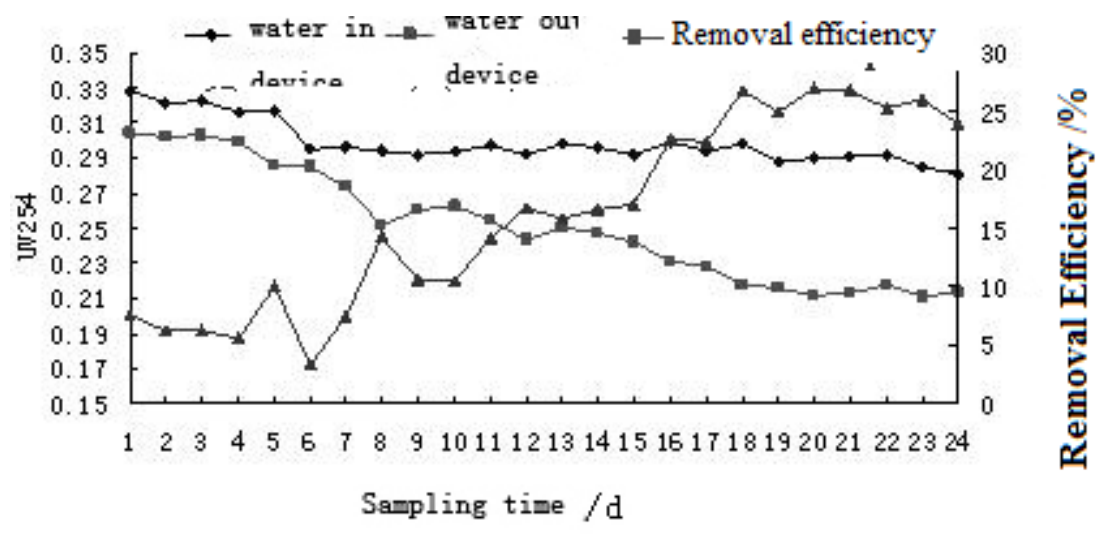

Fig.7 The removal effect of $\mathrm{UV}_{254}$

After 24 days' microbial mucous membrane formation naturally, the removal rate of $\mathrm{UV}_{254}$ reached stable and removal rate was above $20 \%$. 
The removal effect of chrome during microbial mucous membrane was formatting on the Filter material

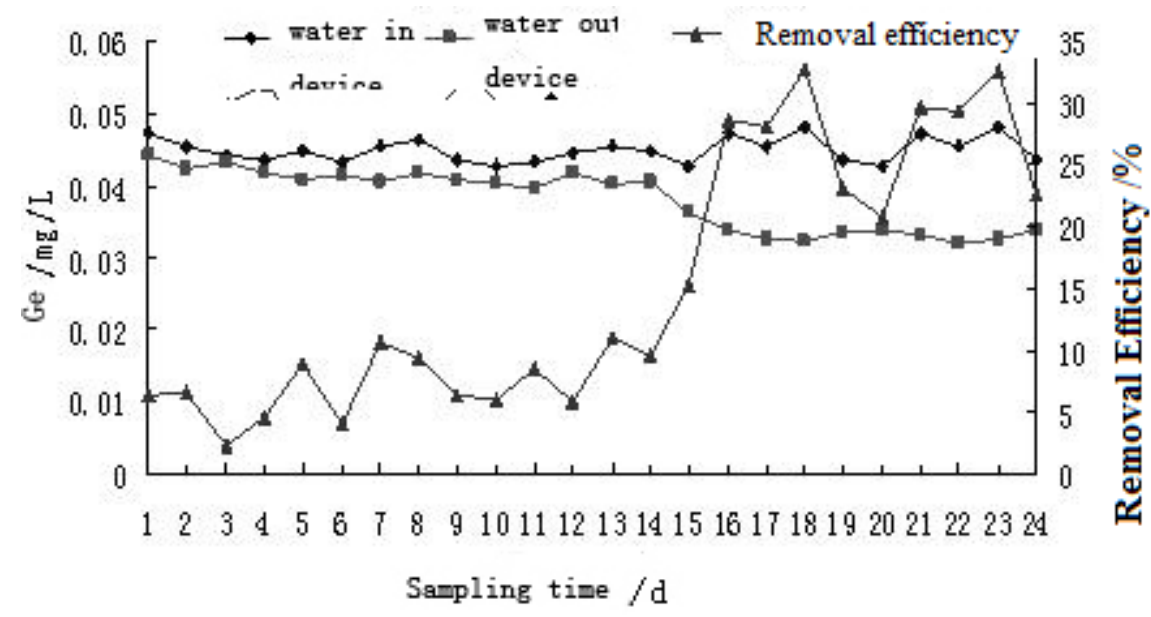

Fig. 8 The removal effect of chrome

We can see that after 24 days' microbial mucous membrane formation naturally, the removal rate of heavy metal chromium reached a higher level and reached $20 \%$, although the removal rate still has some fluctuation,

According to the analysis above, the removal rate of turbidity, $\mathrm{COD}_{\mathrm{Mn}}$, ammonia nitrogen, $\mathrm{UV}_{254}$ and heavy metal chromium all reached stable after operating 24 days by rough filtration plus slow sand biological filtration technics during microbial mucous membrane formatting period, that we can think that after 24 days later, biological filter material reached their maturity.

The treatment effect of the cellar water by rough filtration plus slow sand biological filtration technics

The turbidity removal effect by rough filtration plus slow sand biological filtration technics

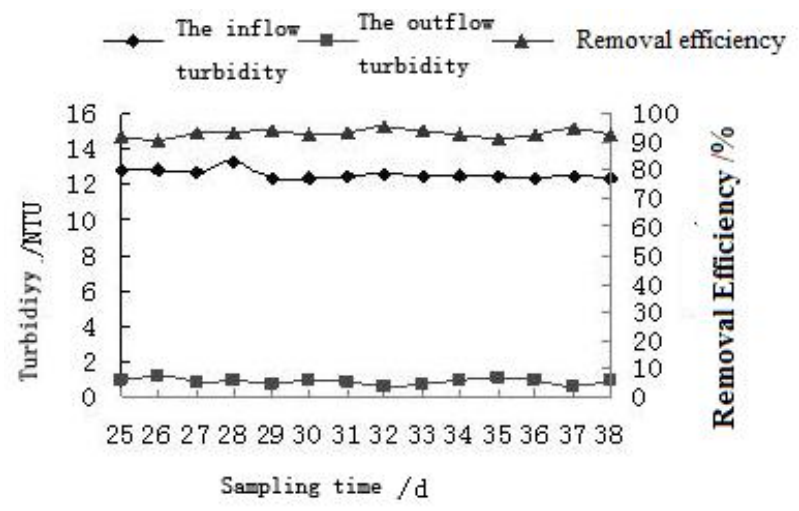

Fig. 9 The removal efficiency of turbidity 
We can see from figure 9, after the rough filtration plus slow sand biological filtration devices running 25 days, effluent turbidity achieved stable. Turbidity of water inflow ranged from 12 to14 NTU was treated by this integrated device and became stable, effluent turbidity was less than 1 NTU, to an average, the turbidity removal rate was around $92 \%$. When the filter material of biological slow filtration became mature, that is to say, after the biological filter with sticky surface membrane formation, adsorption interception effect was fully played, and at the same time, as the existence of the biological mucous membrane, the filter material clearance decreased, and almost all of the suspension impurities in water can be intercepted ${ }^{[7,8,9,10]}$.

The $\mathrm{COD}_{M n}$ removal effect by rough filtration plus slow sand biological filtration technics

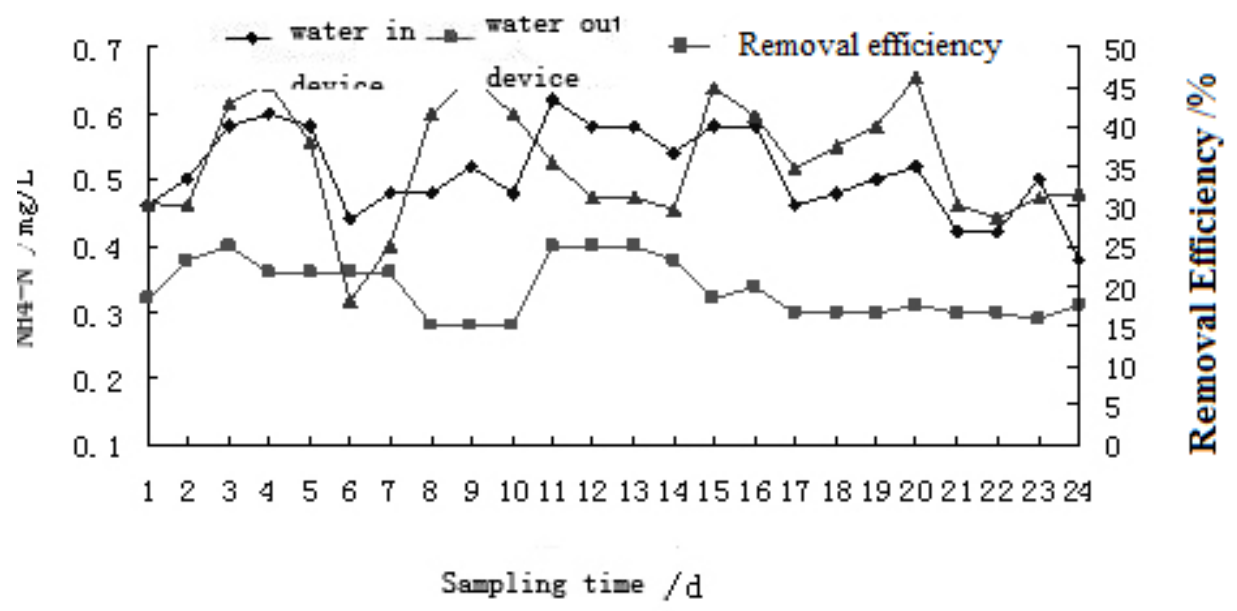

Fig. 10 The removal efficiency of $\mathrm{COD}_{\mathrm{Mn}}$

As we see from figure 10, during the running period of rough filtration plus slow sand biological filtration devices, the removal curve of $\mathrm{COD}_{\mathrm{Mn}}$ presented somewhat fluctuations along with the continuation of operation time. During the slow sand biological filtration was operating, at an average, the $\mathrm{COD}_{\mathrm{Mn}}$ concentration in effluent was $3.1 \mathrm{mg} / \mathrm{L}$, highest $\mathrm{COD}_{\mathrm{Mn}}$ removal rate reached $41 \%$, the average removal rate of $\operatorname{COD}_{\mathrm{Mn}}$ was at about $20 \%$.

The removal of $\mathrm{COD}_{\mathrm{Mn}}$ in cellar water by slow sand biological filtration mainly depended on the biological activity membrane on the surface of the filter material. At the same time, the filter materials with the biological activity membrane attachments can intercept almost all of the suspended materials, thus, the $\mathrm{COD}_{\mathrm{Mn}}$ was removed following the separation of suspended materials, and then the $\operatorname{COD}_{\mathrm{Mn}}$ concentration became lower in cellar rainwater ${ }^{[9,10]}$. 
The ammonia nitrogen removal effect by rough filtration plus slow sand biological filtration technics

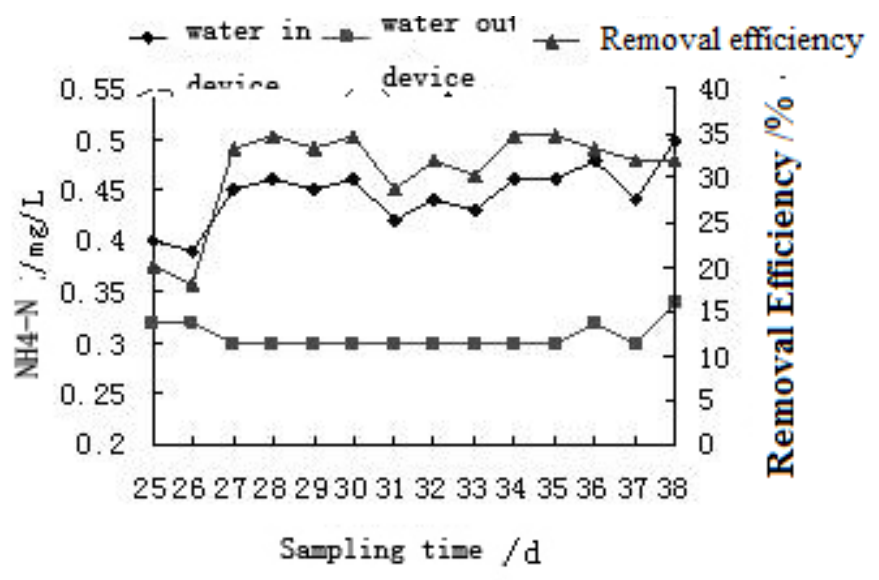

Fig. 11 The removal efficiency of ammonia nitrogen

We can see from figure 11, the ammonia nitrogen removal curve is volatile after the treatment of rough filtration plus slow sand biological filtration technics, but ammonia nitrogen in effluent dropped overall. At the beginning of devices running, ammonia nitrogen in effluent was changed between $0.30 \mathrm{mg} / \mathrm{L}$ and $0.35 \mathrm{mg} / \mathrm{L}$. After 27 days' operation, the ammonia nitrogen in effluent achieve stable and maintain at $0.30 \mathrm{mg} / \mathrm{L}$ or so, removal rate was at about $32 \%$.

Ammonia nitrogen removal function by biological filtration mainly embodied in the following two aspects: One is the ion exchange and adsorption effect of zeolite for ammonia nitrogen. For ammonia nitrogen in cellar rainwater, zeolite has a good ion exchange and adsorption effect, and because of zeolite has a very strong affinity to $\mathrm{NH}_{3}$ polarity molecular, a lot of $\mathrm{NH}_{3}$ can be adsorpted, and thereby, ammonia nitrogen in cellar rainwater can be removed ${ }^{[11]}$. The other hand is that during the biological filtration processing, ammonia nitrogen was took in, absorbed and transformed by microorganism as nitrogen source in biological membrane which was needed for microorganism growth and proliferation.

The $U_{254}$ removal effect by rough filtration plus slow sand biological filtration technics 


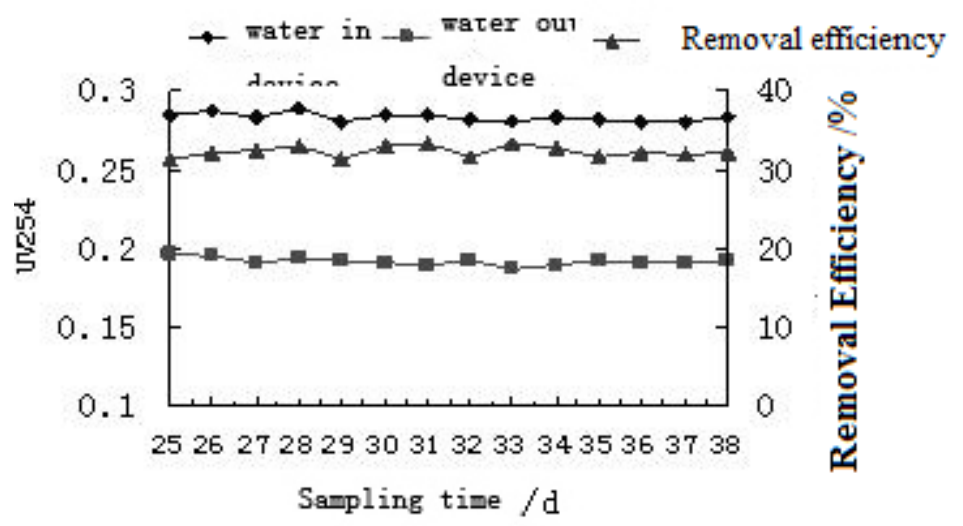

Fig. 12 The removal efficiency of $\mathrm{UV}_{254}$

We can see from figure 12, the $\mathrm{UV}_{254}$ removal curve fluctuated inconspicuous after the treatment of rough filtration plus slow sand biological filtration technics, $\mathrm{UV}_{254}$ in effluent dropped overall. From the 25th day, the decline of removal curve of $\mathrm{UV}_{254}$ in effluent became gradual. $\mathrm{UV}_{254}$ in effluent achieved stable. Cellar rainwater whose $\mathrm{UV}_{254}$ of water inflow ranged from 0.33 to 0.28 was treated by rough filtration plus slow sand biological filtration and after effluent tended to stable, $\mathrm{UV}_{254}$ in effluent reached 0.19 , the average removal rate was at about $32 \%$.

The chrome removal effect by rough filtration plus slow sand biological filtration technics

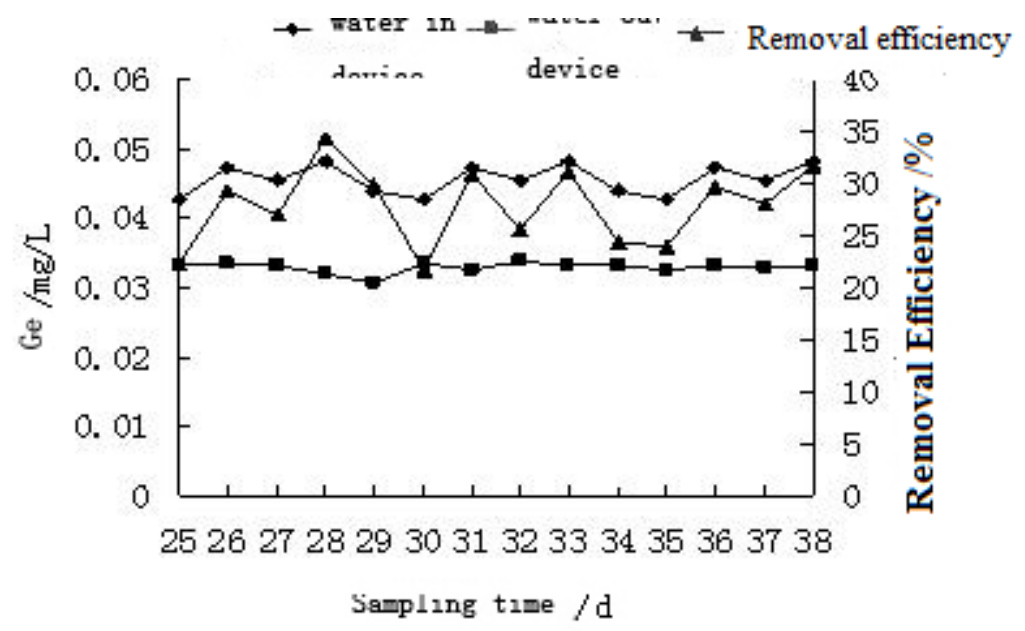

Fig. 13 The removal efficiency of chromium

From figure 13 we know that the chromium removal curve tended to gradual after 25 days' operation, on an average, the removal of heavy metal chromium in the effluent was $0.032 \mathrm{mg} / \mathrm{L}$, removal rate was at about $21 \%$. The removal effect of chromium by rough filtration plus slow sand biological filtration technics mainly depends on the removal effect of chromium by zeolite. Because of the cationic, such as $\mathrm{K}^{+}, \mathrm{Na}^{+}, \mathrm{Ca}^{2+}$ etc didn't unite closely with the crystal lattice frame and the 
coordination key was unbalance in zeolite, so, zeolite has the character of reversible exchange with other cationic in water solution, this react can remove $\mathrm{Cr}(\mathrm{VI})$ in the cellar rainwater.

\section{Conclusions}

(1) Removal efficiency of the two different turbidity in cellar rainwater were obvious after the treatment of rough filtration, dates acquired through the experiments shows that after rough filtration, the removal rates of cellar rainwater with the turbidity for 103 NTU and 53 NTU were $82 \%, 80 \%$, respectively. Effluent turbidity can achieve the requirements which slow sand biological filtration needed.

(2) During microbial mucous membrane formatting period, after the treatment of slow sand biological filtration, the removal rates of turbidity, $\mathrm{COD}_{\mathrm{Mn}}, \mathrm{UV}_{254}$, ammonia nitrogen, chromium respectively reached $90 \%, 24 \%, 24 \%, 25 \%, 20 \%$, and all of the removal effects of the indexes above were good. The microscope examined resort of mud on the surface layer of filter material showed that there were alive microorganisms in biological membrane. After 24 days' microbial mucous membrane formatting, the growth of biological membrane was in a good condition, microbial mucous membrane formation of filter materials generally completed.

(3) After the treatment of rough filtration plus slow sand biological filtration technics, the average removal rates of turbidity, $\mathrm{COD}_{\mathrm{Mn}}, \mathrm{UV}_{254}$, ammonia nitrogen, chromium respectively reached $92 \%$, $20 \%, 32 \%, 32 \%, 22 \%$.

(4) Rough filtration plus slow sand biological filtration technics can effectively deal with the cellar rainwater, this technic produced a perfect removal effect on the common pollutants such as turbidity, Chroma, organic matter, ammonia nitrogen, heavy metal and bacteria and other microbiology indicators in rural cellar rainwater, and after treatment, all the indexes reached national drinking water quality standards, and can be used to purify the cellar rainwater for drinking water in rural areas.

\section{Reference}

[1] Yongsheng Wang, Peihong Li and Yugang Jiang, in: Rural Cellar Water Treatment, Technology of Water Treatment, 25(4): 23-25 (1999).

[2] Fuping Wu, Xiujun Yan, Wei Ren, Guozhen Zhang, Linghua Liu, in: Experimental Study on Treatment of Cellar Rainwater in Northwest Villages by PAC Enhanced Coagulation, Water 
Purification Technology, 29 (2) : 7-9,52(2010).

[3] Fuping Wu, Xiujun Yan, Wei Ren, Guozhen Zhang, in: PAFC and its complex PDMDAAC enhanced coagulation treatment of northwest loess plateau Cellar Rainwater, Journal of Lanzhou Jiaotong University, 28 (4) : 135-139(2009).

[4] Weijia Li, Zhenshan Li, Huazhang Zhao, in: Research Progress in the Application of Ultrafiltration Technology in Treatment of Rural Water Cellar Rainwater in Northwest China, Industrial Water Treatment, 29 (8) : 13-17(2009).

[5] Ruiqiang Yang, Kun Zhu, Xinglong Jin, Yanjun Fang, Youcheng Wen, Hui Chen, in: Cellar Rainwater quality analysis and water quality characteristics, Environmental Research and Monitoring, 14(2):70-71(2001).

[6] Yueque Liu: Modern Instrument Analysis [M].2 edition, Beijing: Higher Education Press: 313-314,170-173(2006).

[7]Li Sheng, Dong Wang, in: Optimization of filtration process and discussion of biological filtration, Liaoning Chemical Industry, 36 (2) : 123-125(2007).

[8]Hongyu Lu, Wenzhuo Lin, Zhiqiang Chen, in: Contact oxidation - biological filtration process pretreatment micro - polluted high turbidity source water, China Water \& Wastewater, 26 (3) : $62-64,68(2010)$.

[9] Fuping Wu, Haiying Qi, Junhong Ding, Guozhen Zhang, Xu Li, Linghua Liu, in: Experimental Study on Treatment of Micro - polluted Cellar Water by Activated Carbon - Quartz Sand Biofiltration, Technology of Water Treatment, 37 (7) : 70-72(2011).

[10] Zhaoyu Bu, Wei Chen, Qiongqiong Xia, in: Study on Biofilm Properties of Drinking Water Bio - enhanced Filtration Process, Water Technology, (1):11-15(2008).

[11] Juan Ma, Kun Zhu, Jiantao Yang, in: Applied Research of Zeolite in Manifold Rainwater, Environmental Research and Monitoring, 16(9): 6-8(2003). 